\title{
МЕТОДИЧЕСКИЕ УСЛОВИЯ ЭФФЕКТИВНОГО ПРИМЕНЕНИЯ ДИДАКТИЧЕСКИХ ИГР В ПРЕДМЕТНОМ ОБРАЗОВАНИИ КУРСАНТОВ
}

\section{METHODOLOGICAL CONDITIONS FOR THE EFFECTIVE USE OF DIDACTIC GAMES IN THE SUBJECT EDUCATION OF CADETS Yu. Goroshilova}

Summary: The article presents the results of a study on the approbation of a methodological training system with the active use of didactic games in the process of training cadets at the military Institute of the VNG of the Russian Federation (branch of knowledge - Pedagogy). The main methodological conditions for the successful application of the game method are revealed. Such methodological conditions include: introduction of changes in the educational and methodological support of the discipline; development of the idea and plan of classes; methodical preparation of the teacher for the use of the game method and training of students.

Keywords: pedagogy, methodical system of training, methodological conditions, didactic game, cadets, military institutes.
$\mathrm{B}$ ажным вопросом в системе образования на протяжении многих лет является его качество. Перед преподавателями военных институтов ВНГ РФ постоянно стоит вопрос повышения эффективности приобретения компетенций обучающимися. Один из наиболее эффективных способов решения этой проблемы - повышение заинтересованности обучающихся в процессе обучения, активизация познавательной деятельности на занятиях и развитие творческих способностей. Решению этих задач способствует применение на учебных занятиях методов, активизирующих познавательную и творческую деятельность обучающихся, позволяющих сделать процесс изучения дисциплин насыщенным и интересным - игровых методов [1].

Анализ публикаций по вопросам применения дидактических игр в теории и практике образовательного процесса свидетельствует о том, что исследования проводились в основном с целью изучения эффективности их применения в техническом $[2,3,4,5,6]$, экономическом $[7,8,9,10,11]$ и дошкольном образовании. Работы, посвященные анализу эффективности применения дидактических игр в предметном обучении «Педагогике» курсантов военных институтов ВНГ РФ, отсутствуют. В связи с этим тема является актуальной как в научном, так и прикладном отношении.

\author{
Горошилова Юлия Алексеевна \\ адъюнкт, Санкт-Петербургский ордена Жукова \\ военный институт ВНГРФ \\ uusay2000008@mail.ru
}

Аннотация: Статья представляет собой результаты исследования по апробации методической системы обучения с активным использованием дидактических игр в процессе обучения курсантов в военном институте ВНГ РФ (отрасль знания - Педагогика). Раскрываются основные методические условия успешного применения игрового метода. К таким методическим условиям относятся: внесение изменений в учебно-методическое обеспечение дисциплины; разработка замысла и плана проведения занятий; методическая подготовка преподавателя к применению игрового метода и подготовка обучающихся.

Ключевые слова: педагогика, методическая система обучения, методические условия, дидактическая игра, курсанты, военные институты.

Повышение эффективности обучения курсантов военных институтов войск Росгвардии «Педагогике» невозможно, если не реализуются принципы сознательности, практикоориентированности, высокого уровня трудности в обучении и др. Одним из направлений деятельности, имеющих целью решение проблемы повышения эффективности обучения, выступает использование дидактических игр. Однако успешное применение игрового метода предполагает глубокое понимание того, какие методические условия должны быть при этом выполнены.

Методические условия - это комплекс обстоятельств, предполагающих выполнение правил подготовки и проведения занятий для достижения запланированных результатов обучения курсантов военных институтов ВНГ дисциплине «Педагогика» с активным использованием дидактических игр.

В исследовании к методическим условиям эффективного применения дидактических игр в предметном образовании в процессе обучения курсантов «Педагогике» были отнесены:

1. Внесение изменений в учебно-методического обеспечения дисциплины. Переработаны методические разработки для проведения учебных заня- 
тий: общие организационно-методические рекомендации по изучению тем; учебно-методические материалы к учебным занятиям (лекционным, семинарским, практическим и контрольно-проверочным занятиям, самостоятельной работе); организационно-методические указания и рекомендации к занятиям; учебные материалы; слайдовое сопровождение.

2. Разработка замысла и плана проведения занятий с их обсуждением на заседаниях предметно-методической комиссии кафедры. Разработка замысла включает в себя:

- обоснование (учебных, воспитательных и развивающих) конечных и промежуточных, четко диагностируемых результатов, которые должны быть получены в процессе проведения занятия с применением игры;

- отбор и компоновка в учебные вопросы информационного материала в соответствии с обоснованными результатами;

- определение контуров сценария дидактической игры, которая максимально будет способствовать достижению обоснованных результатов с использованием отобранного информационного материала;

- предвидение вопросов занятия, которые могут вызвать трудности у обучающихся и потребуют усилий в разъяснении;

- определение способов разъяснения материала в случаях выявления пробелов в знаниях;

- расчёт времени и последовательности представления вопросов занятия с учетом их сложности, объема и наличия уже имеющихся знаний;

- определение порядка контроля полученных знаний и формы получения обратной связи с обучающимися.

План проведения занятий является основным документом преподавателя ВООВО на занятии и представляет собой его модель, вытекающую из замысла руководителя. В плане раскрываются: название темы; цели занятия; категория обучающихся; время; место; приемы и методы обучения; учебная литература; учебно-материальная база, необходимая для проведения занятия; структурная последовательность занятия (с раскрытием учебных вопросов и временем, отводимым на их изучение, описанием действий курсантов в ходе занятия, порядок его завершения и формой контроля учебной деятельности на занятии).

3. Методическая подготовка преподавателей к проведению занятий с активным использованием дидактических игр. В исследовании подготовка включает в себя:

- разработку преподавателем дидактической игры по изучаемой теме в соответствии с программой обучения и планируемыми на занятие задачами. При разработке дидактической игры руководитель занятия должен ответить на вопросы:

- чему нужно научить курсанта (?);

- используя какие ресурсы, он может эффективно научить его (?);

- готов ли обучающийся к эффективной учебной деятельности (?);

- учет особенностей учебной группы при подготовке дидактической игры (уровня профессиональной подготовленности, характера взаимоотношений, в т.ч. лидерства-подчинения, сплоченности и др.). Знание особенностей позволяет корректировать учебно-воспитательные цели, алгоритм и темп решения учебной задачи, технологии проведения игры в зависимости от оказываемого эффекта на группу;

- определение индивидуально-личностных особенностей обучающихся, в целях:

а) выбора руководителем занятия стиля преподавания (наставнический, авторитарный, смешанный) и технологии проведения игры в зависимости от оказываемого от них эффекта на группу;

б) принятия решения о раслпределении ролей в учебной группе;

- определение содержания дидактической игры, с учетом отводимого на занятие времени и максимального охвата обучающихся;

- подготовку необходимых дидактических материалов и учебно-материальной базы;

- подготовку к игре самого преподавателя: осмысливание хода игры, своего места в ней, технологий и методов активизации обучающихся (руководитель игры должен спроецировать проведение игры, предвидеть трудности возможные в ходе ее проведения и продумать варианты их решения для предупреждения срыва занятия);

4. Методическая подготовка обучающихся к проведению занятий с активным использованием дидактических игр. Проведению учебных занятий по экспериментальной методической системе обучения дисциплине «Педагогика» должна предшествовать консультация обучающихся и заблаговременная выдача заданий на подготовку к игре. Целесообразно на консультации довести до обучающихся инструкцию к игре и ее правила, с использованием, например, постановки проблемных вопросов. Это позволит: выявить уровень знаний изученного теоритического материала; прийти к общему пониманию ими цели дидактической игры; снизить риск смещения цели учеб- 
ного занятия на второстепенные вопросы; увеличить время на проведение дидактической игры на учебном занятии (групповое обсуждение, выступления и практическую отработку поставленных в ходе игры задач).

\section{Bыво $\triangle$}

Повышение эффективности и качества учебных занятий предполагает использование методов и техноло- гий, способствующих реализации принципов сознательности, практикоориентированности, высокого уровня трудности в обучении и др. К таким методам относятся дидактические игры. Их применение требует обязательного выполнения таких методических условий, как: внесение изменений в учебно-методическое обеспечение дисциплины; разработка замысла и плана проведения занятий; методическая подготовка преподавателя к применению игрового метода и подготовка обучающихся.

\section{ЛИТЕРАТУРА}

1. Кругликов В.Н. Интерактивное обучение в высшей школе: проблемы и перспективы // Научно-технические ведомости Санкт-Петербургского государственного политехнического университета. Общество. Коммуникация. Образование. 2013. №184. URL: https://cyberleninka.ru/article/n/interaktivnoeobuchenie-v-vysshey-shkole-problemy-i-perspektivy (дата обращения: 08.09.2021).

2. Кругликов В.Н. Деловые игры и другие методы активизации познавательной деятельности / В.Н. Кругликов, Е.В. Платонов, Ю.А. Шаранов; Санкт-Петербургская акмеологическая акад. (ин-т). - Санкт-Петербург: П-2, 2006 (СПб.: Тип. "Наука"). - 189 с.; ISBN 5-93893-324-2 монография

3. Гурина И.А. Формирование познавательной самостоятельности студентов технического вуза средствами дидактических игр: автореф. дис. ... канд. пед. наук. СПб., 2002. 19 с.

4. Воробьева 0.Н. Система разработки и применение игр в высшей школе СССР и США: Сравнительный анализ: автореф. дис. ... кандидата педагогических наук. Алма-Ата, 1989. - 28 с.

5. Ханнанова-фахрутдинова Л.Р., Хацринова 0.Ю., Иванов В.Г. Организация и проведение дидактических игр в технологическом вузе // Вестник Казанского технологического университета. 2008. №6. URL: https://cyberleninka.ru/article/n/organizatsiya-i-provedenie-didakticheskih-igr-v-tehnologicheskom-vuze (дата обращения: 08.09.2021).

6. Н.И. Куприянычева, Э.Б. Куприянычева Некоторые аспекты активного обучения в условиях технического вуза //Вестник Казанского тнхнол. ун-та. 2012, №10, C.404

7. Солопенко Е.В. Метод деловых игр в системе подготовки специалистов в области экономики: автореф. дис. ... канд. пед. наук. СПб., 2004. 24 с.

8. Арзуханова С.А. Формирование профессиональной компетентности специалистов экономического профиля в вузе средствами игровых технологий: на примере предметной области «Иностранный язык»: автореф. дис. ... канд. пед. Наук. Ульяновск, 2009. 27 с.

9. Грэм Р.Г. Руководство по операционным играм [Текст]: пер. с англ. / Р.Г. Грэм, К.Ф. Грей; под ред. Ф.В. Широкова. - М.: Сов. радио, 1977. - 376 с. Перевод изд.: Business games handbook/ Robert G. Graham, Clifford F. Gray (Amer. management assoc., 1969).

10. Орусова О.В. Применение метода деловых игр при преподавании курса «Макроэкономика» // Вестник МФЮА. 2012. №2. URL: https://cyberleninka.ru/ article/n/primenenie-metoda-delovyh-igr-pri-prepodavanii-kursa-makroekonomika (дата обращения: 08.09.2021).

(с) Горошилова Юлия Алексеевна (uusay2000008@mail.ru). 